\title{
The Strategic Planning Process and Current Practices: A Comparative Empirical Study of UMW Toyota Motor and Chemical Company of Malaysia
}

\author{
Gholamreza Zandi ${ }^{1}$, Muhamed Sulaiman ${ }^{1}$, Hala Mohammad Al Atiyat ${ }^{2} \&$ Babak Naysary $^{1}$ \\ ${ }^{1}$ Kulliyyah (Faculty) of Economics and Management Sciences, International Islamic University Malaysia (IIUM), \\ Malaysia \\ ${ }^{2}$ Dar Al-Hekma College, Jeddah, Saudi Arabia \\ Correspondence: Gholamreza Zandi, Accounting Dept., Kulliyyah (Faculty) of Economics and Management \\ Sciences, International Islamic University Malaysia, Kuala Lumpur, 53100, Malaysia. Tel: 60-3-6196-4651. \\ E-mail: zandi@iium.edu.my
}

Received: March 12, 2013 Accepted: May 7, 2013 Online Published: June 28, 2013

doi:10.5539/ass.v9n9p185 URL: http://dx.doi.org/10.5539/ass.v9n9p185

This paper was presented in the International Conference on Business Management (ICBM). Izmir, Turkey. April 2012.

\begin{abstract}
This article focuses on the strategic planning process and its best practices that is suggested by the literature and also applied by companies. The two cases studied in this paper are two prominent, non-competing companies operating in Malaysia namely UMW Toyota Sdn. Bhd. and the Chemical Company of Malaysia-Fertilizers Division (CCMFD). Applying a comparative qualitative case study research methodology, the major objective of the study is to investigate in depth the different aspects, processes and practices employed by these well-known companies for their strategic planning processes. Using the grounding theory as a framework of analysis, the research findings revealed common as well as distinctive strategic planning practices between the companies under the study. The output of this project is a set of best practices to strategic planning that are followed by UMW Toyota as well as CCMFD. In the light of the findings of this research and also referring to the literature, some recommendations are made for the best practice of strategic planning process in companies.
\end{abstract}

Keywords: CCMFD, Grounded theory, strategic planning process, UMW Toyota Sdn. Bhd.

\section{Introduction}

\subsection{Research Problem}

Strategies planning process has been an increasing subject of research in the recent years. Many companies, consultants and academics have tried to explain where companies excel and where they fall short in their strategic planning process (Kang \& Zhou, 2012). However, the literature lacks a comprehensive explanation on how successful companies and strategic planners perform this planning. Given the increasing complexity and dynamic of the business environment (McKay, Murray \& Hui, 2011), the researchers seek to find out how the strategic planning is conducted by top companies and also whether it is done according to guidelines of strategic management books or it is different when it comes to practice within different industries and business contexts.

Through a comparative case study, this research has generally focused on the strategic planning process of two pioneer companies from two different industries operating in Malaysia. These companies are UMW Toyota Motor Sdn. Bhd. and CCM Fertilizers Division. The main purpose of selecting these companies was to reach an understanding of the idea (concept), practices and challenges behind the strategic planning processes from the perspectives of those who are leaders in this field. Moreover, the research aspires to come up with a set of best practices, processes and guidelines that can be used by other companies to achieve competiveness and sustainability. 


\subsection{Research Objectives}

According to the above statements, this research seeks the following objectives?

1) To understand the different dimensions of the strategic planning process applied by top companies known for their exceptional strategic planning and compare these practices with the theories and processes suggested in the literatures.

2) To study the challenges and critical success factors of strategic planning process that are sought by companies in general and by UMW Toyota and CCM Fertilizes Division in specific through in depth case study on practices that caused successful implementation and achievement of strategic objectives.

3) To interpret the effect of the strategic planning on the companies' strategic direction and overall companies' performance.

\section{Literature Review}

In the early twentieth century, Henri Fayol proposed the principles of management as planning, organizing, commanding, coordination and controlling. Though this model defines the functions of management in a simple but comprehensive way, it seems to lack one element that would direct manager's efforts towards the overall corporate goals given the uncertainty in which today's organizations operate. That element is strategic thinking. Strategy is a term that describes a holistic long term approach to all the basis facets of the management and business-development processes (Jofre, 2011). Without being strategic, managers, regardless of their managerial level, will lack the understanding of the dynamics of the business environment, overlook opportunities and merely produce results that are aligned with the organization's overall objectives (Freeman, 2010).

\subsection{Strategic Planning Process}

Strategic management is defined as a set of decisions and actions that result in formulation and implementation of plans designed to achieve a company's objectives (Pearce \& Robinson, 2009). It includes analyses, decisions and actions an organization undertakes in order to create and sustain competitive advantage (Dess, Lumpkin \& Eisner, 2007). Because of continuous change and uncertainty in today's business environment, strategic planning gained more popularity in the recent years. Classically, the objective of strategic planning is to achieve a balance between the external environment, and the internal capabilities of the firm. For this purpose, the strategic managers identify critical tasks through a process which is known as the strategic management process. Though, there are many models for this process, the basic components are the same in all strategic management literature (Dye \& Sibony, 2007; Dess, Lumpkin \& Eisner, 2007; Pearce \& Robinson, 2009; Jofre, 2011). This process is the approach currently used by strategic planners and it has the following main phases: analysis, formulation and implementation, evaluation and control. The following is an explanation of each of these phase and the most important issues that concern the strategic planners.

\subsection{Strategic Analysis}

This phase is concerned with the analysis of the current strategic goals, analysis of the external environment, and analysis of the internal environment that would help companies envision their way to the future (Pearce \& Robinson, 2009). Taking into account that the future direction of the business is no longer dependent solely on the internal capabilities of the companies, managers need to keep an eye on the external environment and continuously monitor its dynamics to be able to foresee emerging opportunities and threats (Acure, 2006). During strategic planning, companies collect internal and external data as input for their strategic planning process. Internal inputs include financial and operational data while external inputs include environment and market forecasts. strategic analysis are usually done through top management meetings in which strategic issues that will have the greatest impact on future business performance are discussed (Dye \& Sibony, 2007). These discussions are usually initiated by ideas, key problems, environmental trends, and proposals prepared by operational managers (Acure, 2006). Some companies designed strategic planning teams which undertake this phase through in-depth interviews with all senior managers and some corporate and business executives. The outcome here is a list of major strategic issues to be administered. The strategic planning team then prioritizes the list items and assigns managers to investigate each and prepare a report within a specific time. The outputs of this phase are usually broad objectives and directions from senior managers to capture the opportunities or counter the threats (Dye \& Sibony, 2007).

\subsection{Strategy Formulation and Implementation}

This phase is related to identification of competitors, establishing long term objectives, generating alternative strategies and choosing a particular set of strategies to pursue. Once the strategy choices are identified, an 
implementation plan consisting of annual objectives, functional-level strategies, tactics, and plans are established to bring the intended strategies to reality. According to Dye \& Sibony (2007) research, $25 \%$ of the managers stated that their companies have a strategic plan but they lack practical measures. This means that having a strategy plan as an output of the formulation phase is worthless if it was not supported with an implementation plan. Usually, this gap is there in companies in which those who plan (e.g. senior managers, strategy planning team, etc.) are different than those who execute the strategy (French, 2009). On the other hand, the differences in the company's environments have created different views between strategic planners related to the critical aspects of the strategic plan such as formality, flexibility, planning cycle, timeframe, and participants.

\subsubsection{Formality of the Strategic Plan}

There is a controversial debate among practitioners of strategic planning on whether the strategic planning process should be formal or informal. Supporters of informal strategic plans believe that that they are flexible and adaptive while opponent of informal strategic plans believe that they are without structure and lack clear directions (Rudd, Greenly \& Beatson, 2008). But studies conducted in this area show that managers prefer a formal approach to deal with strategic planning. In companies that adopt informal strategic planning, $51 \%$ of the managers were dissatisfied with their approach while only $20 \%$ of the managers in companies that adopt a formal strategic planning process expressed the dissatisfaction (Dye \& Sibony, 2007). Nevertheless, the formality of the strategic plan evolves and becomes more structured as the business grows throughout its lifecycle. In this sense, companies with more formal planning process tend to have specific objectives, written action plans, clear division of responsibilities and use sophisticated planning tools and software to aid managers in facing major strategic issues (Acure, 2006). As the business develops and becomes more complex, there is a need for the strategic planning to become more formalized and explicit to guarantee the effective communication of corporate objectives and strategies throughout the firm (Elbanna, 2008).

\subsubsection{Flexibility of the Strategy Plan}

Strategic planning aims to help managers predict changes in the environment and be prepared to take informative decisions when unexpected events occur. Therefore, a very critical element of a strategic plan is flexibility. Flexibility is defined as the extent to which alternative decisions are generated and considered in strategic planning, allowing for positive organizational change and adoption to environmental turbulence (Rudd et al., 2008). To keep the strategic plan flexible, a system of continuous evaluation and update is needed to establish a link between the strategic plan and the company's competencies (Goncalves, 2009). Flexibility allows companies to be more capable of adapting to the environmental and business forces, making the right decisions promptly, efficiency allocation resources and therefore enhancing the effectiveness of their strategic planning which eventually results in better performance (Rudd et al., 2008). Previous studies have showed significant relationship between strategic planning and performance but with flexibility as a mediating factor.

\subsubsection{Planning Cycle of the Strategic Plan}

Some companies plan for their strategic planning process while others do not. Between these two extremes, there are the majority of companies that believe that there is no need to undertake major strategic redirection every for planning cycle. Some alternate between business units while others use trigger mechanisms to decide which business units will undergo a full strategic-planning exercise in a particular year (Dye \& Sibony, 2007). The key here is that when there are important changes in the internal or external environment, altering plan is essential. With today's turbulent business environment, companies are facing higher risk and unstable earning and growth. This requires them to formulate their strategies more often than before (Speculand, 2009).

\subsubsection{Timeframe of the Strategic Plan}

Due to the uncertainty of the current global business environment, companies tend to plan their strategies more frequently and consequently the strategies timeframe is also becoming shorter. It was found that most companies have formal plans for the period of 12 to 18 months which usually include some elements of a company's strategy, budget, financial and operating targets, and compensation metrics (Allison \& Kaye, 2005).

\subsubsection{Participants in the Strategic Planning}

In business world, everyone talks about stockholder's involvement as a key factor to successful achievements of objectives. Identifying the participants of the strategic plan means that we need to understand who the most relevant people are that can contribute to the process and create healthy interactivity. Strategic conversations will have little impact if they involve only strategic planners from both the business unit and the corporate levels. It is believed that those who formulate the strategy should also perform it (Allison \& Kaye, 2005). This demands that there should be cooperation between top management and other managerial levels in a participative way which 
can bring informative, effective and creative results to the implementation of the strategy (Elbanna, 2008).

\subsection{Strategy Evaluation and Control}

This phase includes four main activities: following up with the execution of the corporate, business and functional level plans, measuring the performance to know whether the implemented strategies are achieving their intended results or not, monitoring changes in the internal and external factors that may have effect on the implemented strategies, and taking corrective actions when necessary (David, 2007). According to Speculand (2009), business success is achieved more by how well strategies are implemented than how good the strategy is to begin with. He also found that in average nine out of ten strategies fail to be implemented successfully. This can be explained by the lack of effective, continuous evaluation and control system. This was supported by Dye's \& Sibomy (2007) findings that $45 \%$ of the planning process fails to follow up with the execution. To ensure successful implementation, a set of steering controls should be in place to steer the firm in cases of unexpected changes in the external environment or variation in the internal implementations of the strategic plan (Pearce \& Robinson, 2009). For this purpose, usually regular reviews with related business managers are scheduled to guarantee transparency and efficiency of the implementation of the strategic plan and to discuss major issues of concerns and emerging trends in the external formal strategic performance management systems that combine financial and non-financial indicators that can give an early warning of developing from the strategic plans. Another way that top companies practice to enhance chances of successful implementation is to tie their strategic implementation to manager's performance evaluation and compensation schemes which proved to bring about long-term commitment and motivation of managers to implement the strategic plan and detect and solve problems.

The objective here is to help companies be proactive rather than reactive and influence, anticipate and initiate events rather than responding to them. To achieve this objective, it requires top management commitment and should actively involve managers and employees at all levels of the organization in order to reflect its dynamic nature.

\section{Research Methods}

The research is an exploratory qualitative research, as its goal is to find how companies undertake their strategic planning within the real-life context and to uncover the best practices adopted by top companies. The applied part of the research is a comparative case study on two companies operating within two different industries in Malaysia. These companies are UMW Toyota Motor Sdn Bhd and CCM Fertilizers Division.

\subsection{Sampling Method}

Unlike quantitative research which uses a random sample generalizable to a larger population, qualitative research uses a purposive sampling method. Purposive sampling involves selection of informants based on an important characteristic under study (Lewis, Saunders \& Thornhill, 2009). This study selected UMW Toyota Motor Sdn Bhd and CCM Fertilizers Division mainly for the following purposes:

1) Sizable, reputable companies: the researcher was looking for a sizable company (more than 200 employees) that is well-established (more than 10 years) and has a strong presence in the Malaysian Market (strong brand name).

2) Accessibility to information

\subsection{Data Collection Methods}

In accordance with the research method, multiple sources of data collection were used. Data was collected from those decision makers involved in strategic planning and implementation. Supplementary email interviews were critical to cover-up some gaps and to collect missing data. Prior to the interviews, all background information about the companies, their history, strategic objectives, operation, and services were obtained from the internet, companies' annual reports and previous researches. The interviews results were then combined with other documentary evidence provided by each organization to produce a detailed case study report on each one. The reports were then returned to the interviewees to be checked for accuracy. When accuracy was confirmed, the case study evidence was deemed suitable for analysis. Besides, secondary data were gathered from books, academic journals and web sites along with online databases to understand the history of the strategic planning, the underlying theories and traditional practices studied in the literature.

\subsection{Content Analysis}

The analysis of the data collected employed a two-step content analysis procedure that comes from a discussion of grounded theory (Seidel, 1988). This included the following stages: 
1) Noticing/Collecting: through open coding, the researcher categorized data collected from the interviews and documents obtained into phenomena through close examination of the data. Coding was done with themes identified from a priori ideas that emerged in the literature review and that were the major ideas of the research questions. Additional information and clarifications were requested from the interviewees through email for themes that lacked clear data about the two companies under the study.

2) Thinking: the researcher closely examined the data by looking for similarities and differences in the perceptions, dynamics and practices related to strategic planning between the two companies under the study. The: findings were: then synthesized in a compare and contrast mode between companies and also with the findings from the literature review. Moreover, some explanations were given for outstanding phenomena.

The patterns the researcher observed across the two organizations permitted inferences regarding the strategic planning process from the perspective of those who lead it. Analysis of the transcribed interviews and documents yielded five major themes summarized in Table 1.

Table 1. Data analysis themes

\begin{tabular}{|c|c|c|}
\hline & Theme & Ideas \\
\hline & Strategic Planning & $\begin{array}{ll}\text { - } & \text { The idea of Strategic Planning } \\
\text { - } & \text { Scope of the Strategic Planning } \\
\text { - } & \text { Strategic Planning Model }\end{array}$ \\
\hline $2-$ & Analysis Phase & $\begin{array}{ll}\text { - } & \text { Process } \\
\text { - } & \text { Sources of information } \\
\text { - } & \text { Forecasting tools }\end{array}$ \\
\hline $3-$ & Formulation and implementation Phase & $\begin{array}{ll}\text { - } & \text { Planning cycles and Timeframe } \\
\text { - } & \text { Participants } \\
\text { - } & \text { Approach } \\
\text { - } & \text { Process } \\
\text { - } & \text { Alignment } \\
\text { - } & \text { Approval } \\
\text { - } & \text { Dissemination }\end{array}$ \\
\hline $4-$ & Evaluation and Control Phase & $\begin{array}{ll}\text { - } & \text { Role of Strategic Planning team } \\
\text { - } & \text { Performance management systems }\end{array}$ \\
\hline $5-$ & Challenges & \\
\hline $6-$ & Critical success factors & \\
\hline
\end{tabular}

\section{Data Analysis and Results}

In this section, the data collected from the interviews and documents about the strategic planning process of the two companies under the study i.e. UMW Toyota Motor Sdn Bhd and CCM Fertilizers' Division, are organized and interpreted based on the six themes resulted from the coding process.

\subsection{Theme 1: Strategic Planning}

Strategic planning which include idea, scope and model used in the process is presented and discussed in this part separately for two firms.

\subsubsection{The Idea of Strategic Planning}

UMW Toyota Motor Sdn. Bhd.: "The more the company plan, the better it can cope with unexpected events"; this is the basic belief of chairman of the process about strategic planning. For him, the goals of strategic planning are not too different from theory. First of all, strategic planning is done to protect the interests of the company not only in terms of profit but also the welfare of others. Apart from a perfect solution, UMW Toyota tries to have a solution that is acceptable by all stakeholders through coordinating between the departments. Due to the 'helicopter' view of the entire company's organizational structure that the strategic planning team has, they are 
able to fill the coordinating gap.

CCM Fertilizers Division: Mainly, strategic planning is a systematic way to achieve the strategic targets of the division. It is needed for CCM Fertilizers Division to achieve its long term strategy of moving towards a high end business which focuses more on manufacturing high quality fertilizers and less on trading, in other words the management has been very aggressive in its investment and growth strategies and visualized CCM fertilizers as a strategic element of its bigger supply chain and strategies planning is believed to be the vital tool that would help all operational departments and companies to align their goals to the Division goals.

\subsubsection{Scope of Strategic Planning}

UMW Toyota Motor Sdn. Bhd.: UMW Toyota is a joint venture between Japan's Toyota Motor Corporation and UMW Group which owns 51\% of the share. This entails equal representation in the board and therefore, decisions are made jointly. Specifically, all investment related decisions are taken jointly but funding is domestic. The Strategic Planning department mainly plays a functional role in terms of coordinating between views, interests and needs, and maintaining the coherence of the strategies of eleven divisions, and its subsidiary Assembly Services Sdn. Bhd. Figure 1 illustrates UMW Toyota Motor organizational chart and the departments that are part of the annual strategic plan. The strategic Planning Department is responsible for risk and crisis management planning, economic research and corporate level reports and presentations. However, the responsibility of implementation of the strategy lies with the operating divisions but the role of strategic Planning Department is to ensure that the operating divisions discharge its responsibilities. Review right and wrong decisions and share learnt lessons with each other.

CCM Fertilizers Division: After 2004,CCM Fertilizers authorities it found the need to develop a formal long term (i.e. three year) strategic plan with great focus on organic growth in production of high quality fertilizers rather than trading: a movement towards high end business. For this reason, it created the body that is responsible for and leads and control the process of strategic planning which is the Business Accounting, Strategy and Special Projects Department. The role of the head of the department is to facilitate all forecasting, formulation and implementation meetings related to the strategic objectives, consolidate proposed plans and follow up with the implementation. Figure 2 shows CCM Fertilizers Organizational chart and the departments that are part of the annual strategic plan.

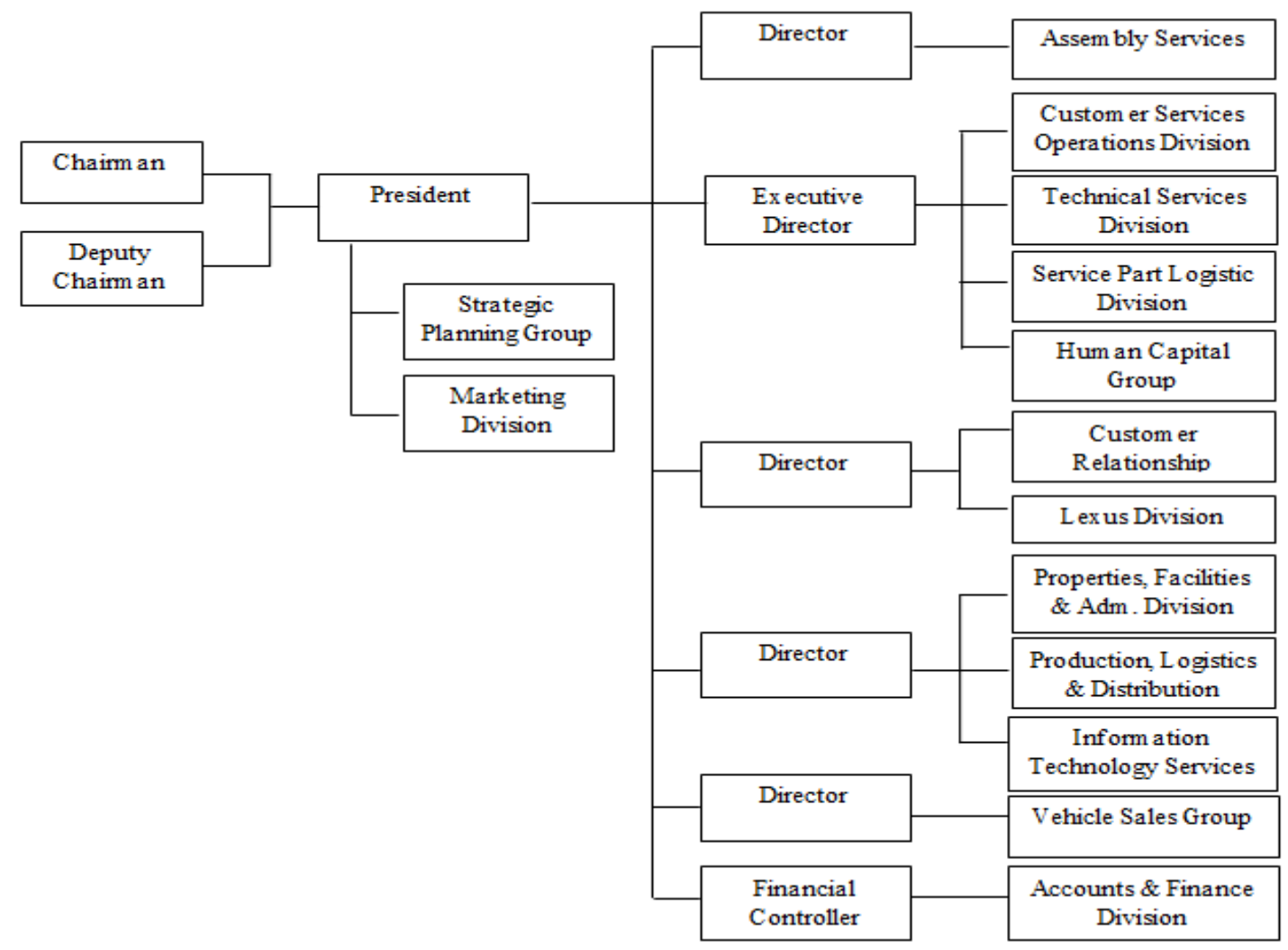

Figure 1. UMW Toyota Motor Sdn. Bhd organizational chart 


\subsubsection{The Model of Strategic Planning}

In the UMW Toyota Motor the strategic planning process is framed based on the famous Deming (Shewhart) cycle; i.e. PDCA (Plan, do, check, act) this framework implied that the process of strategic planning is an on-going process and the implementation of PDCA involves lots of functions. However, the emergence of unexpected or unplanned events invokes new cycles of the PDCA. The major body that is responsible for and lead and control this process is the Strategic Planning Department.

However the strategic planning process in CCM Fertilizers Division is framed based on the traditional process of strategic management which constitute of three major phases: analysis, formulation and implementation, and evaluation and control with few sub-phases under each phase. Through this process, analysis and control are on-going process while formulation and implementation phase of the strategy takes place in the third quarter of the business year. The major body that is responsible for and lead and controls this process is the Business Accounting, Strategy and Special projects department.

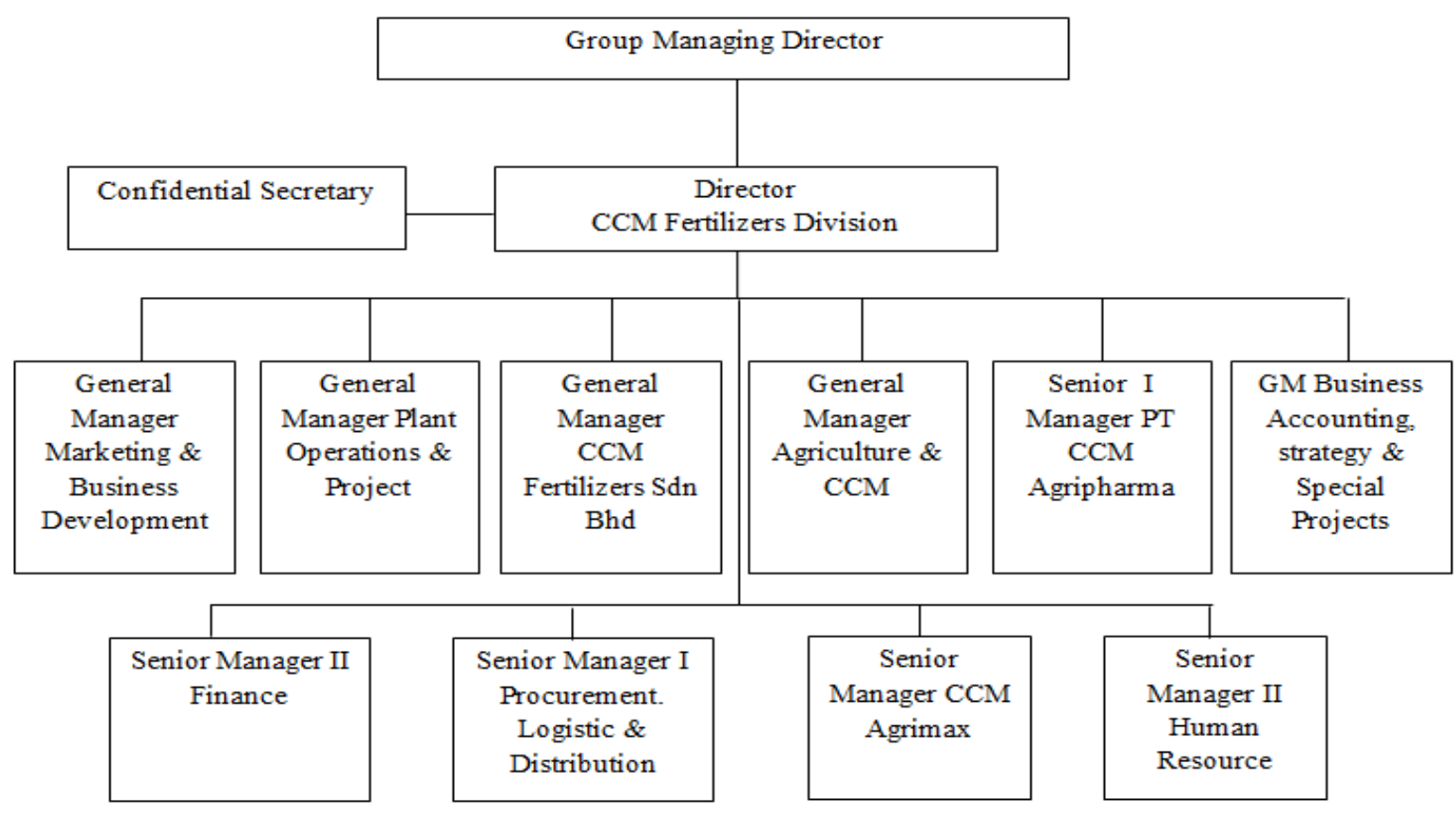

Figure 2. CCM fertilizer division organizational chart

\subsection{Theme 2: Analysis Phase}

UMW Toyota takes direct approach to analyse the internal and external environment in which it operates in order to feed its strategic planning. Throughout this phase, no sophisticated analysis or forecasting tools are used; just simple analysis and reporting along with brainstorming meetings. In this phase, UMW Toyota goes through: Its vision, mission and guiding principles, Economic Analysis, Market Analysis, Industry Dialogue (especially competitors), Stakeholders Analysis and Internal Analysis in every parts of the firm. External information is obtained from multiple sources. They can obtain from all channels of media. If the required information cannot be obtained from published or official sources, it will be sought from research house which UMW Toyota have got links with. And if the research house has got no information, the Japanese practice of the Gemba, which means 'the real place', is most often successful. This means that the strategic planning department will approach the company outlets, managers and salespeople to find out and report on information critical to the future of the company.

Nonetheless in this phase, every year CCM look at: Vision and mission, Financial Resources, Market and environmental trends (i.e. political directions, industry trend and major domestic and regional economic trends). The projection exercise using scenario analysis sessions is done for every year covering the next three years. Sources of external information are either published information or through CCMF informal intelligent 
networks' records and other sources such as suppliers, partners and customers. The intelligent networks constitute of salespeople on the ground that informally monitor the performance and news of the competitors, customers and general market trends such as competitors pricing or production strategies. The outcome of the process is a weekly report to the marketing department and usually will feed the strategic planning formulation and review.

\subsection{Theme 3: Formulation and Implementation Phase}

This theme generally covers issues such as planning cycles and timeframe and the participant of the strategic planning in both firms. This theme also lists approaches and alignments through strategic planning process. Final parts of this theme are general approval of the plan and dissemination of the plan respectively.

It was mentioned earlier that UMW Toyota adopts the PDCA (Plan, do, check, and act) model for its strategic planning. However, the formulation of annual planning exercise takes place in the third quarter of the business year at the same time the formal annual review of performance is taking place. The plan which covers a timeframe of one year is to be formulated and brought to existence through absolute consensus of all participants. The process of formulating the strategy is done as the following stages:

Review Stage which taken place in the third quarter of the year to take into account what the company achieved in the current year. This gives the planners an idea on how the performance should be for the rest of the year and for the coming year. Brain Storming is the next stage in which the process of formulating the strategy is done through a series of formal brainstorming meetings with pre-set agendas. Beside the Strategic Planning team, the participant of the strategic planning formulation meetings are the directors at all levels, who are considered the CEOs of their respected areas. The results of these meetings are a set of annual targets required to meet the company objective while considering market conditions and internal capabilities. In Division Planning Stage each division is to prepare their detailed annual functional plans accordingly. The division plans are consolidated by the Strategic Planning Department and are examined to see if they will meet the targeted goals, in the next step which is called Consolidation Stage. The outcome is a detailed, formal documented annual strategy. UMW Toyota believes that, to be successful, a participatory approach is effective and everybody must agree with all elements of the proposed strategic planning. The process is continued by the Approval Stage in which, a summary of the consolidated plan is submitted to top management for approval. Dissemination of the plan is the final stage. After approval the strategy is active and should be disseminated to all employees by the heads of the divisions. They are expected to translate what the strategy means to their own operating division and help their employees see their roles in the successful implementation of the new strategy.

The approach to formulating the strategy in CCM Fertilizers Division is intensively participatory and may require 10-15 meetings; this process takes place within the third quarter of the business year. However, the budget plan is mainly done by the Finance and Business Accounting and Strategy departments. No involvement of any external party or strategic consultants occurs in this process. The formulation of the strategic plan goes through the following stages:

Brainstorming meetings that headed by the general managers (GM) of Business Accounting, Strategy and Special Projects departments, all CCMF heads of departments and companies meet to discuss major projection through scenario analysis give the current financial capabilities. The outcome from this stage is broad targets and parameters related to the expansion opportunities, products and raw material, production volume, sales and profits, efficiency and corporate social responsibility (CSR). Next stage is called Involvement stage in which, managers at lower levels are involved and asked to prepare their action and budget plans that would achieve the parameters set in the previous stage. Construction stage is taken place after the consolidated plan is ready. Then another round of meetings at the level of head of departments and companies is started. All aspects of the plan must be agreed upon and eventually the strategic objectives are set. The outcome of these meetings is the three-year strategic plan which includes topics such as Economic outlook, Industry trends, Market outlook, Goals and objectives, Key focus areas, Action plans and strategies, Manpower plan, Historical information and Three-year forward finance plan. Final step is called Approval stage. After the strategic plan is ready, a presentation is prepared and is presented in three stages for approval to CCMF Director and the Group Finance Director, the CCM Group Chairman and to the board of directors.

\subsection{Theme 4: Evaluation and Control Phase}

This phase develops the role of strategic planning team followed by a review of the systems in which performance is monitored to know whether performance of every division is toward achieving the strategic goals or not. 
As mentioned before, the responsibility of the implementation of the strategy in UMW Toyota lies with the operating division. The role of the Strategic Planning Department is to ensure that the operating divisions perform according to the targeted plan. Performance control systems that applied to keep control on the implementation of the strategy are: Daily Reporting, Monthly Meetings and Quarterly Review Meetings.

Although the division which is in charge of evaluating in CCM Fertilizers Division is different, the whole process almost follows the same scenario in both companies. In CCM Fertilizers Division once the plan is approved, the implementation of the plan is done at all levels. The major role of the Business Accounting, Strategy and Special Projects department is to monitor the implementation of the strategy and continuously evaluate and coordinate the performance is monitored by Key Performance Index (KPI) and the performance management requires preparation of the following types of reports: Monthly Performance Report, Monthly Management Meeting, Quarterly Performance Report and Management Council Meeting.

\subsection{Theme 5: Challenges of Strategic Planning}

The major challenges that face the strategic planners at UMW Toyota that are described by the head of the Strategic Planning Department are, to overcome the existing culture that resists change as the biggest challenge and to have open, healthy communication between divisions. However, the most important challenges which CCM Fertilizers Division face as stated by Business Accounting, Strategy and Special projects department are, to achieve consensus, bridging the gap between the upper and lower level managers and getting the support from top management.

\subsection{Theme 6: Strategic Planning Critical Success Factors}

In this phase the vital elements which tend to a successful strategic plan are displayed for both firms one after another.

UMW Toyota Motor Sdn. Bhd.: In the case of UMW Toyota Motor Sdn. Bhd. the major critical success factors mentioned by the chairman of the strategic planning process are the following:

- All decisions, big or small, are to be taken in consultation with all participants in the strategic planning process and all are to be via consensus.

- The strategic planning process is not to be complicated for the participants and the planning team.

- Knowing how to prioritize is a very vital skill and should be nurtured within the strategic planning team and participants.

- The implementation of PDCA should be an on-going process.

- Critical to the success of any strategic planning process is the accuracy of information at all stages of the PDCA.

- One of the other practices that UMV Toyota considers is Gemba which means going down to the real ground. Gemba practically means going to the place that things are happening and problems are emerging in reality.

- Clear, understandable and timely communication of the strategy to all levels of the organizational members using a language that is commonly understood by all employees regardless of their intellectual level.

- What is important for UMW Toyota is a culture that encourages everyone to question 'why'.

- Systematic follow up while learning from the past.

- In formulized meetings there is a tendency to filter out the bad and only show what is good. Thus, it is critical to encourage a culture of self-responsibility and present the fact even if it is not desirable.

- So, in order to evolve throughout the, one has got to have a broad mind to see all possibilities and believe in change while not forgetting basic values.

CCM Fertilizers Division: In case of CCM-Fertilizers Division, the major critical success factors mentioned by the chairman of the strategic planning process are the following:

- Effective participation of all those who carry out the strategy and are responsible for its implementation.

- Top management support for the strategic plan and the process. According to the chief of strategic planning team "top management support is the foundation of the strategy for any organization, without which we can forget about the whole process".

- Critical to the creation of an accepted strategy is to facilitate a healthy, open communication between all participants. 
- Being able to understand other stakeholders' needs and interests and address them in the strategy.

- Strategic goals should be achievable though challenging, and linked to the annual incentive plan in order to motivate everyone.

- Provide continuous support and guidance to managers at all levels during implementation of the strategy.

- Having a system of periodic review of achievements and challenges related to the strategic plan.

- Apply variance analysis to dig deep and understand the real causes of any variation between planned and actual results.

- The ability to identify critical data, whether internal or external that are relevant to the strategic goals of the division. Having this ability guarantees quality inputs to the strategic planning process.

- Communication of the approved strategy to all employees is critical as their contribution is a prerequisite for the successful implementation of the strategy and eventually the success of the company.

\section{Conclusion}

Initially, this project is an explanatory case study research that aimed at explaining the dynamics of the strategic planning process as it is implemented by two Malaysian companies known for their sustainable growth namely UMW Toyota Motor Sdn. Bhd. and CCM Fertilizers Division.

UMV Toyota is perceived to be less formal as their process is said to be simplified. We conclude that the process is not structured rigidly compared to CCMF process which obviously looks very formal, systematic and standardized with predefined tasks and outcomes of each phase. Both companies' strategies are flexible as they are subject to review every quarter and the analysis phases of both companies were found to be very similar to what the literature suggested. For its external analysis, UMW Toyota is found to depend more on formal information sources such as published data and research centres, while CCMF depends more on its informal market intelligent records. UMW Toyota's strategy is more shaped by internal capabilities rather than external and industry forces. The strategic planning team perceives the political, economic, competitive environment as stable and healthy. This may be explained by the fact that UMW Toyota is currently and for the nineteen consecutive years is the number one producer and distributer of non-local cars in the Malaysia market and is satisfied with its market position and market share. On the other hand, CCMF puts higher emphasis on government policies, economic trends, market competition and customers' need. These forces strongly direct CCMF strategy within the internal financial constraints.

Though its business environment is perceived to be stable, UMW Toyota strategic planning is very short term oriented i.e. one year plan. This contradicts with previous studies that linked between the instability of the environment and the tendency to have short term strategy. However, UMW Toyota annual strategic plan covers corporate level, business level and functional level strategies. On the other hand, CCMF strategic planning is long term oriented, i.e. three year plan, with very specific budget, action plans and human resource plans. The strategic plan covers all levels of strategy namely corporate, global, business and functional.

Both companies take a participatory approach to strategic planning. Through the major brainstorming, strategy construction and presentation meetings are confined to top management, lower level managers are involved in crafting the action plan that are needed to achieve the new strategic goals. No other external parties are involved at this phase. There are also some other similarities between these two companies such as: in both companies, the body responsible for strategic planning (i.e. Strategic Planning Department in UMW Toyota and the Business Accounting, Strategy \& Special Projects Department in CCMF) plays a key role to ensure successful implementation of the strategy through continuous follow ups and well-defined performance management systems. In addition the leaders of the strategic planning process at both companies agree on the challenge of facilitating effective, open and healthy communication between participants to bridge the communication gap between different operational divisions and to balance their needs with the company's overall objectives.

UMW Toyota is very distinctive on its way to continuous development. This principle was very clear in their strategic planning process. Everyone is encouraged to question everything such as the process, practices, decision, plans and performance. The ultimate objective is to share success and failures with all employees at all levels and make sure that the company is continuously going ahead of everyone. Meanwhile, CCM Fertilizers Division is very distinctive in its strategic planning practices. It has a very formal, well-structured system that provides high quality strategic plans that combine qualitative and quantitative targets and challenging benchmarks for three years in advance. In these strategic plans, resources are to be utilized efficiently and every dollar is to be justified. 
Taking into account that the results of these two cases cannot be generalized but still there are some findings which are common between these two firms and also the literatures and underlying theories which is worth considering in the process of strategic planning for any company and organization.

- The strategic plan is to be flexible and continuously subject to review.

- Top management commitment and support for the strategy is essential for its successful formulation and implementation.

- At the formulation phase of the strategic planning process, all aspects of the strategy are to be decided by participants via consensus.

- During all phases of the strategic planning, the type, quality and accuracy of input information are to be verified to avoid wrong decision.

- For the process to be effective and efficient, facilitating open and healthy communication between participants, managers and departments is essential at all phases.

- The strategic plan has to be communicated to all employees to be aware of the general direction of the company; it's the strategic objectives and their roles in realizing these objectives.

- Having a clear, periodic performance management system to evaluate progress, achievements and challenges is crucial.

- The last best practice we observed rather than directly mentioned is that the strategic management process is to be centralized in one entity/department and this entity is to be responsible for coordinating between other departments, managers, interests and view, leading the process of formulating the strategy and follow up on its implementation.

\section{References}

Acure, N. (2006). Assesment of strategy formulation: How to ensure quality in process and outcome. International journal of operations \& production management, 26(1), 69-91. http://dx.doi.org/10.1108/01443570610637021

Allison, M., \& Kaye, J. (2005). Strategic planning for nonprofit organizations: A practical guide and workbook. Wiley.

David, F. (2007). Strategic management concepts (11th ed.). New Jerrcy: Pearson education, Inc.

Dess, G., Lumpkin, G., \& Eisner, A. (2007). Strategic management: text and cases (3rd ed.). New York, McGraw-Hill/ Irwin.

Dye, R., \& Sibony, O. (2007). How to improve strategic planning. The McKinsy Quarterly, 3, 40-48. Retrieved form http://search.ebscohost.com

Elbanna, S. (2008). Planning and participation as determinants of strategic planning effectiveness. Management decision, 46(5), 779-796. http://dx.doi.org/10.1108/00251740810873761

Freeman, R. E. (2010). Strategic management: A stakeholder approach. Cambridge University Press.

French, S. (2009). The Deductive Frame. Journal of Management Development, 28(3), 242-266. http://dx.doi.org/10.1108/02621710910939622

Gonçalves, H. S. (2009). Proposal of a strategy model planning aligned to the balanced scorecard and the quality environments. The TQM Journal, 21(5), 462-472. http://dx.doi.org/10.1108/17542730910983380

Jofre, S. (2011). Strategic Management: The theory and practice of strategy in (business) organizations. DTU Management.

Kang, J., \& Zhou, J. (2012). Analysis for Theory of Integrated Resource Strategic Planning Based of Power Balance between Supply and Demand. Asian Social Science, 8(15), 136. http://dx.doi.org/10.5539/ass.v8n15p136

Lewis, P., Saunders, M. N., \& Thornhill, A. (2009). Research methods for business students. Pearson.

McKay, S., Murray, M., \& Hui, L. P. (2011). Pitfalls in Strategic Planning: Lessons for Legitimacy. Space and Polity, 15(2), 107-124. http://dx.doi.org/10.1080/13562576.2011.625222

Pearce, J., \& Robins, R. (2009). Formulation, implementation and control of competitive strategy (11th ed.). New York, McGraw-Hill/Irwin. 
Rudd, J. M., Greenly, G. E., Beatson A. T., \& Lings, I. N. (2008). Strategic planning and performance. Journal of business research, 61(2), 99-108. http://dx.doi.org/10.1016/j.jbusres.2007.06.014

Seidel, J. (1998). Qualitative data analysis. The ethnography, (5). Retrieved February 1, 2010, from http://ftp.qualisresearch.com

Speculand, R. (2009). Six necessary mind shifts for implementing strategy. Retrieved January 27, 2010, from http://ezinearticles.com

\section{Copyrights}

Copyright for this article is retained by the author(s), with first publication rights granted to the journal.

This is an open-access article distributed under the terms and conditions of the Creative Commons Attribution license (http://creativecommons.org/licenses/by/3.0/). 